\title{
Do sinal à significação: lições do curso de comunicação de Gilbert Simondon
}

Demétrio Rocha Pereira'

https://orcid.org/0000-0003-0762-8469

I - UFRGS

Porto Alegre (RS). Brasil

Resumo: Este artigo discute e desdobra questões centrais do curso de Gilbert Simondon sobre a comunicação, ministrado entre os anos de 1970 e 1971 e publicado apenas em 2010. Entende-se que o filósofo francês, que tem recebido crescente aclamação póstuma, propõe uma teoria da comunicação original, ainda por ser assimilada em nossa área. Como parte de um esforço de reconstruir essa teoria, este texto apresenta os principais argumentos de Simondon no curso de 1970-71 e, a partir de uma confrontação com a teoria da informação, defende a significação como conceito-chave para uma comunicação orientada no sentido de uma ciência das transformações.

Palavras-chave: Simondon; teoria da comunicação; significação; semiótica.

\begin{abstract}
From signal to signification: lessons from Gilbert Simondon's course on communication
- This paper discusses and unfolds the main topics of Gilbert Simondon's course on communication, lectured between 1970 and 1971 but published only in 2010. We believe that the French philosopher, who has been receiving a growing posthumous acclaim, brings forth an original theory of communication, still to be assimilated by our field. As a step towards rebuilding such theory, this text presents the main arguments from Simondon's course and, confronting them with information theory, defends signification as a key concept for understanding communication as a science of transformations.
\end{abstract}

Keywords: Simondon, communication theory; signification; semiotics.

De tímido impacto enquanto trabalhava e vivia o seu autor, a obra de Gilbert Simondon (1924-1989) vem crescendo em interesse desde a virada do século, com uma renovada oferta de traduções e a tardia edição de volume único, em 2005, das duas partes de sua tese sobre a individuação, defendida em 1958. Esse reavivamento concerne 
diretamente à comunicação, pelo que a filosofia simondoniana mobiliza de modo original o conceito organizador de nossa área. É já desde aquela tese, que lança o conceito de informação contra a dupla forma e matéria do hilemorfismo aristotélico, que Simondon faz com que a comunicação seja coextensiva ao Ser e participe de toda individuação seja de um átomo, de um ser vivo ou de um grupamento social:

O verdadeiro princípio de individuação é a mediação, supondo, geralmente, dualidade original de ordens de grandeza e ausência inicial de comunicação interativa entre elas, e então comunicação entre ordens de grandeza e estabilização. (SIMONDON, 2013, p. 27, trad. nossa)

Pouco mais de uma década adiante, entre 1970 e 1971, a comunicação aparece como preocupação central para Simondon (2010) em um curso que trava conversa com a cibernética e, embora sem referir seus autores, com o modelo de comunicação tornado clássico pela teoria matemática da informação (SHANNON; WEAVER, 1964).

Publicado apenas em 2010, o curso nos permite distinguir as principais diferenças de Simondon face a um dos modelos fundadores da ciência da comunicação, notadamente a sua atenção à significação, ou a efetiva ação transformadora da comunicação. Como parte de um esforço mais amplo de reconstruir uma teoria da comunicação simondoniana, este artigo apresenta os principais argumentos de Simondon no curso de 1970-71, do qual depreende a significação como conceito-chave para uma comunicação fundamentada enquanto ciência das transformações.

\section{A transformação como critério}

Já nas primeiras linhas de sua nota introdutória para a teoria matemática da comunicação de Claude E. Shannon, Warren Weaver esclarece que a comunicação, segundo tal abordagem, inclui "todos os procedimentos pelos quais uma mente [ou mecanismo] pode afetar outra[o]" (SHANNON; WEAVER, 1964, p. 3, trad. nossa). Embora a comunicação aí se estabeleça como capacidade de transformação, assumindo inclusive o interesse de influenciar condutas, a explanação que se segue não contempla o afeto ou a mudança. Erigida em torno de intenções de comando, essa teoria da comunicação só cede à mente afetada a chance de, no melhor dos casos, espelhar uma engenharia complexa cujo estudo pertence inteiramente ao âmbito da mente que afeta. Cabe à mente que afeta codificar uma mensagem em sinais, enquanto a mente afetada faz o jogo inverso, decodificando sinais para, idealmente, copiar sem distorções a mensagem que chega. Uma comunicação bem-sucedida resulta, assim, de uma equalização de mentes, paradigma que fornece as bases para a digitalização do mundo: comunicar é copiar arquivos de lado a lado. O esquema, entretanto, não se pretende informático, mas extensivo à linguagem e ao pensamento: para a fala humana, entende-se que o cérebro codifica informação 
em sinais a serem emitidos por um aparelho fonador para um ouvindo receptor, de onde a mensagem prossegue, enfim, para a decodificação pelo cérebro do destinatário.

Grande parte da inteligência matemática de tal teoria se assenta na possibilidade de escolha de uma mensagem pelo polo emissor. O termo informação, de fato, mede o grau de liberdade de escolha entre diferentes mensagens possíveis, a quantidade de informação mantendo relação inversa com a probabilidade de seleção simbólica: quanto mais improvável, mais informativo o sinal. O elogio da incerteza acaba por constranger esse projeto de entendimento total, pois se reconhece que o ruído aumenta a quantidade de informação, procedendo-se, então, a uma distinção forçada entre incerteza desejável (informação) e incerteza indesejável (ruído). O caráter impositivo do esquema não se manifesta apenas sobre o destinatário, incidindo também sobre o canal, compreendido como possível fonte de ruído. Tanto o ouvinte quanto os materiais envolvidos na engenharia da comunicação devem se curvar à intenção do falante. Pode-se sentir aí um desejo de desmaterialização que, pelo acesso direto ao outro, gostaria de liberar a comunicação de toda mediação, o que, bem entendido, encaminha o apagamento do outro: se reservo ao outro não mais do que a função de repetir o que envio, a comunicação se torna palavra de ordem, e a alteridade, um incômodo.

Apenas cinco anos após a publicação seminal de Shannon e Weaver, Wilbur Schramm (1955) complexificaria o modelo para considerar um receptor responsivo (capaz de feedback) e a influência de liames sociais (campos de experiência) sobre processos de codificação/decodificação necessariamente banhados em certas crenças e valores. Como o receptor então devolvesse sinais para o emissor, numa efetiva troca de lugares, o diagrama passava a ser circular, apresentando a comunicação como via de mão dupla. O tráfego informativo, entretanto, ainda se passa entre indivíduos. Ponto crucial em que investirá Simondon, o questionamento dos contornos individuais não ganhará a atenção dos continuadores do modelo clássico de Shannon e Weaver, que permanecem compromissados, ademais, com uma política do entendimento exercida desde a perspectiva emissora. No caso específico de Schramm, essa tendência se expressa em uma preocupação desenvolvimentista que abastecerá as cartilhas da Unesco para auxiliar o terceiro mundo a "alcançar os patamares das sociedades desenvolvidas" (MELO, 2007, p. 18). O artigo de Marques de Melo é esclarecedor, mostrando como a difusão do modelo comunicacional de Schramm na América Latina responde a uma agenda geopolítica declarada.

Justamente por travarem intimidade com vontades institucionais, não raro fazendo a comunicação concorrer em favor da ordem, as pioneiras mobilizações sociológicas do modelo matemático passam a se ocupar da maleabilidade da recepção; mas permanecemos constritos a um esquema que remete, em última instância, à intenção do falante, a exemplo do que defende em 1960 David Berlo, para quem o objetivo da comunicação "é tomarmo-nos agentes influentes, é afetarmos os outros, nosso ambiente físico e nós 
próprios, é tomarmo-nos agentes determinantes, é termos opção no andamento das coisas. Em suma, nós nos comunicamos para influenciar - para afetar com intenção" (BERLO, 1999, p. 20).

Nos cursos coligidos em Comunicação e Informação, Simondon (2010) não redesenha o esquema de Shannon e Weaver, mas vira a mesa, rechaçando a intencionalidade do emissor e situando no receptor o protagonismo da comunicação. É que o interesse recai, agora sim, sobre a transformação como exigência do acontecimento comunicacional: "A informação não pode se definir fora desse ato de incidência transformadora e da operação de recepção" (SIMONDON, 2010, p. 159, trad. nossa). Não importa o que alguma mente quis dizer e sequer que haja emissor: a informação só é informação pelas transformações que efetivamente opera em um meio irritável. A questão passa a ser, então, o que constitui a suscetibilidade desse meio, que não se deixa confundir com inércia ou passividade. Se o foco mudou de lado é porque a transformação será atribuída ao desdobramento dos potenciais de um sistema dinâmico - o que não é dizer sistema passivo, totalmente aberto, mera via de passagem para séries causais; nem sistema fechado, homogêneo, desprovido das tensões internas que lhe permitiriam ser afetado.

Receber, no sentido que Ihe confere Simondon neste curso, equivale a ativar comunicação interna. Um tal acontecimento depende do encontro de pelo menos duas realidades diferentes e não-enclausuradas em si mesmas. A realidade incidente Simondon nomeia singularidade, disparadora de um processo indefinido de atualização de potenciais, descartada qualquer correspondência quantitativa entre causa e efeito: como uma faísca na floresta, a informação mais mínima pode se propagar do micro ao macro, escorando-se nas tendências latentes do meio em que se amplifica. Em seu exemplo predileto, Simondon observa como um germe estrutural captura a energia potencial de uma solução líquida amorfa para disparar um processo de cristalização:
a estrutura inicial do germe não pode incitar positivamente a cristalização de um corpo amorfo se ele [o corpo amorfo] não estiver em equilíbrio metaestável: é necessária uma certa energia na substância amorfa que recebe o germe cristalino; mas, assim que o germe está presente, ele possui o valor de um princípio: sua estrutura e sua orientação escravizam essa energia do estado metaestável; o germe cristalino, trazendo consigo não mais que uma energia muito fraca, é no entanto capaz de liderar a estruturação de uma massa de matéria vários bilhões de vezes maior que a sua. (SIMONDON, 2013, p. 86, trad. nossa)

Reaparecendo como condição de um receptor passível de transformação, a metaestabilidade remete aos níveis de energia de um sistema, tal como definidos e investigados em termodinâmica: acima do seu limiar mínimo de energia, o sistema perdura em relativo equilíbrio, dito metaestável, enquanto uma incidência energética externa não precipite a sua transição para o estado fundamental de menor energia, ou ponto zero. Nem equilíbrio nem desequilíbrio plenos, portanto, mas antes um equilíbrio incerto, pois 
o sistema dispõe de uma potência de transitividade como reserva de estruturações futuras, em estado latente:

Pode-se chamar de natureza essa carga de indeterminação; não se deve concebê-la como pura virtualidade (noção abstrata de certa maneira oriunda do esquema hilemórfico), mas como verdadeira realidade carregada de potenciais atualmente existentes como potenciais, ou seja, como energia de um sistema metaestável. A noção de virtualidade deve ser substituída pela de metaestabilidade de um sistema. (SIMONDON, 2013, p. 304, trad. nossa)

No exemplo do cristal, a noção de metaestabilidade impede pensar em um líquido puramente amorfo que, em seu caráter contínuo, seria efetivamente impotente, ou seja, não cumpriria as condições para o acontecimento informativo. O estado amorfo designa antes um estado desordenado, desprovido de direções privilegiadas, algo comparável à "nebulosa onde nada está necessariamente delimitado" referida por Saussure (2006, p. 130) ao tratar do pensamento e do som antes de sua delimitação recíproca pelo "aparecimento da língua".

A singularidade incidente, por sua vez, é para esse meio tensivo que a recebe, de modo que o evento comunicacional define tanto ela quanto o papel de receptor, estabelecidos ambos no ato mesmo do seu encontro. O receptor nasce na chegada da singularidade estruturante, acolhendo de fora a indução de um processo de transformação. Isso não descarta que um meio pleno de potenciais produza as suas próprias transformações, ressalvando-se que, nesse caso, não são satisfeitas as definições de receptor. O que importa reter aqui é a solidariedade entre esses termos, que designam as duas faces de um encontro, instauradas pelo encontro, relativas uma à outra.

Como veremos, não carece que a comunicação ocorra entre dois ou mais sistemas, pois um sistema em equilíbrio metaestável, pela própria diferença interna que o atravessa, comunica consigo mesmo, constituindo-se de acoplamentos, de múltiplas negociações entre as suas partes.

\section{Comunicação em três níveis: ecologia, etologia, psicologia}

$\mathrm{Na}$ abertura de seu curso sobre a comunicação, Simondon reforça a pertença desse objeto de estudo à sua pesquisa anterior: "A comunicação está ligada à individuação e não pode se operar sem ela" (SIMONDON, 2010, p. 59, tradução nossa). Desta vez, a definição de comunicação passa pela palavra acoplamento [couplage] e, de início, deve passar entre dois ou mais sistemas metaestáveis, em detrimento de junções internas a um mesmo sistema, as suas diferentes partes estabelecendo não ainda comunicação, mas solidariedade. Simondon, entretanto, é rápido em acrescentar que "o fenômeno é fundamentalmente o mesmo; pode-se dizer que há comunicações no interior de um sistema [ressonância interna] e entre sistemas" (SIMONDON, 2010, p. 60, trad. nossa). 
Como observa Jean-Yves Chateau (2010), estamos diante da perspectiva de uma comunicação geral, que toca inclusive o interior da matéria (aparentemente) inerte ${ }^{1}$, e devemos considerar acoplamentos comunicativos átomos-átomos, máquinas-máquinas, máquinas-meios etc. A única condição, repetimos, é que ao menos um dos termos envolvidos seja suscetível de transformação a partir de uma incidência energética, ainda que mínima.

O autor organiza seu curso segundo três níveis de comunicação e tomando quase sempre o organismo vivo como caso de estudo. A gradação exprime uma aquisição progressiva de graus de liberdade²: o primeiro nível engloba interações do tipo estímuloresposta, em que uma comunicação de feitio circular se estabelece entre o ser vivo e o seu meio, incluindo-se aí o interior das células, onde se define a passagem ou a inibição de moléculas; a comunicação alcança, em seguida, seres similares porém assimétricos, vivos ou artificiais, que dialogam com o auxílio de um código e da emissão repetitiva de sinais; por fim, a circulação se dá no interior de um mesmo sistema multifásico capaz de aprendizagem e invenção.

O exame do primeiro nível se concentra na seleção sensorial de sinais a partir do ruído de fundo, do que decorre a individuação de um som, de um objeto, de um cheiro etc. Essa seleção não respeitaria critérios como o de intensidade do sinal, reportando-se antes a certos gatilhos do organismo. A comunicação acha aqui os seus requisitos nos limiares perceptivos e nas preferências seletivas dos corpos: assim que o ouvido humano, por exemplo, esteja especialmente propenso a distinguir sinais abarcados pelo espectro de frequências da voz humana. Já a fala não desata sem vantagens fisiológicas como as de não produzir eco nem arrasto sonoro, o que possibilita a sua aparição como objeto definido e facilmente decomponível. É desde limiares corporais, portanto, que já vai se decidindo a distinção figura/fundo, ou sinal/ruído, do que resulta que os problemas de significação, em Simondon, não possam se furtar a um perspectivismo de base fisiológica. Como o filósofo deixara evidente em curso anterior, entretanto, as normas coletivas vêm trabalhar sobre essa base, o contexto social modificando efetivamente "a estruturação da percepção e os mecanismos cognitivos" (SIMONDON, 2012, p. 309, trad. nossa, grifos no original).

No segundo nível de comunicação, Simondon levanta diversos modos de diálogo interespecífico em aves, anfíbios e insetos: um choro pedindo ajuda, um gesto para marcar território etc., sendo ainda necessária, neste estágio, a repetição incessante do sinal. Propriamente etológica, essa comunicação seria eficiente como filtro para que um grupo reconheça os seus e exclua o estrangeiro ou o desviante.

1 Veremos Simondon invocar justamente a comunicação para repreender o substancialismo em filosofia: "O que falta ao esquema hilemórfico é a indicação da condição de comunicação e de equilíbrio metaestável, ou seja, a condição de ressonância interna em um meio determinado, que se pode designar pelo termo físico de sistema" (SIMONDON, 2013, p. 62, trad. nossa). Crítica nos mesmos termos recai também sobre Spinoza, em que faltaria comunicação pois o indivíduo não seria mais do que o modo de uma substância única; e sobre Leibniz, no qual cada mônada individual, exprimindo o Todo, seria uma substância fechada, indivisível, homogênea, autossuficiente e "sem janelas".

2 "O progresso da comunicação desde a simples relação com o meio até a comunicação interna do indivíduo capaz de inventar pode ser concebida como a aparição de novos graus de liberdade" (SIMONDON, 2010, p. 133, trad. nossa). 
A repetição codificante pode ser dispensada quando, com a maior margem de liberdade obtida em terceiro nível, houver capacidade de aprendizagem e invenção - desta vez, destacam-se animais como os golfinhos e os corvídeos, que desenvolvem dialetos locais e conseguem reconhecer/decodificar tais inovações. Não mais trocamos nem transmitimos informação, mas inventamos uma nova dimensão de compatibilidade a partir de realidades antes incompatíveis, tramando um sistema agitado por ressonância interna.

Podemos distinguir em cada nível os seguintes verbos: 1) escolher/preferir; 2) codificar/discernir; 3) aprender/inventar. Assim situada nas comunicações de terceiro nível, a invenção ganha na obra do autor um espaço que, na tese sobre a individuação, ocupava a significação:

Aqui [na invenção], a informação não é o conteúdo de uma mensagem transmitida, mas a significação original da resolução do problema que conduz os incompatíveis ao real. [...] A mais alta comunicação é aquela que se traduz pelo fluxo incessante entre os domínios do sistema organizado pela resolução; essa comunicação traduz o ato principal de organização; ela existe tanto em uma fé religiosa quanto em um tubo eletrônico; esses caos originais coerentes apresentam sempre o duplo aspecto da contradição interna e da unidade funcional; eles não são descritíveis nem sob a forma de encadeamento causal, nem sob a forma de teleologia unilinear: eles têm facetas, eles são multipolares. (SIMONDON, 2010, p. 87 , trad. nossa)

Descrita adiante como "uma comunicação entre comunicações, um sistema de sistemas, instituído a um nível de complexidade superior a qualquer um dos sistemas preexistentes" (SIMONDON, 2010, p. 129, trad. nossa), a invenção se dota de um "senso de autoconstituição de normas" (SIMONDON, 2010, p. 129, trad. nossa). Aqui é onde mais tomamos distância da teoria matemática, pois informação deixa de ser questão de escolher entre as opções (mais ou menos prováveis) providas por um conjunto predeterminado, como quando seleciono uma sequência de caracteres aceitável no acervo de possibilidades cristalizadas de um idioma; desobediência do código, a invenção é (re) codificante, internamente contraditória e descrita, com efeito, em termos de "caos originais coerentes" (SIMONDON, 2010, p. 87). Se do código inferimos um legislativo fixo sobre o campo do comunicável, desconsideramos essa faceta inventiva da informação, que "conduz os incompatíveis ao real". Simondon persegue uma intuição tão aventada quanto negligenciada por Shannon e Weaver - a de que um evento comunicativo, imbuído de um poder de afetar, deve promover transformação. E, enquanto ainda aceitamos preservar os termos daquele diagrama clássico, a invenção fica situada em um receptor graças ao qual podemos distinguir entrada e saída, "termos extremos de uma transformação nãoreversível" (SIMONDON, 2010, p. 161, trad. nossa). 


\section{Transversalidade da significação em relação aos níveis}

Os dois primeiros níveis da comunicação, no entanto, não se definiam pela invenção: o primeiro parecia contente, como o emissor de Shannon e Weaver, em selecionar, enquanto dependia o segundo de sinais reiterativos esteados ainda em um código fixo. Deve então a invenção aguardar pela inteligência inaugural dos golfinhos e dos corvídeos? Chega ela em terceiro nível, para culminar um processo de aquisição progressiva de graus de liberdade? Essa aquisição não é, ela mesma, inventiva na liberdade que adquire? Após quantas invenções pôde algum dia nascer um órgão seletivo, de primeiro nível? De que invenções anteriores depende o código reiterativo e aparentemente estável de segundo nível?

Entendemos que o nivelamento de Simondon serve menos para reforçar, via teoria da comunicação, a ideia darwinista de complexificação progressiva dos organismos do que para concebermos diferentes regimes de comunicação, mais ou menos amigáveis à invenção e mapeáveis em acoplamentos diversos envolvendo entidades físicas, vivas e/ou psíquicas.

Como na sequência físico à biológico à psicossocial, a enumeração dos três níveis de comunicação leva a pensar em etapas sucessivas, mas não há razão para que os regimes mantenham relação de encadeamento linear. Essa consideração é importante para que, em comunicação, o equilíbrio não ganhe precedência genética em relação ao desequilíbrio, quando a filosofia de Simondon quer descrever o inverso: embora esteja cimentado como individuação primária, o regime físico só arranja estabilidade ao consumar um processo transdutivo que nada tinha de estável nem podia ser chamado, enquanto processo, de físico. A transdução não pertence a um ou outro nível. Parece-nos, aliás, que físico, vivo e psíquico se distinguem menos pelo modo de operar do que pelos termos envolvidos na operação (forças materiais da argila ou forças afetivas do sujeito?). A categorização tripartite se reportaria, assim, ao individuado, e não à individuação. Logo que considerada a propagação transdutiva, as fronteiras se embaralham: em um curso de 1962, Simondon (2010, p. 172, trad. nossa) sopesa a hipótese de que podemos encontrar as forças do psíquico desde a individuação vital, faltando-nos razão para vetar a possibilidade de que os "aspectos mais elementares da vida", dotados de consciência, firmariam entre si relações de tipo social. Se cabe estender a noção de sociedade para outras espécies animais, ela poderia ser

mais completamente generalizada, englobar as relações entre vegetais e mesmo entre moléculas; do mesmo modo, a relação de tipo psicossocial, definida de saída entre as relações interindividuais humanas, é suscetível de receber uma generalização. A partir disso, se poderia considerar a existência de uma relação dialética entre a relação psicossocial, a relação social pura, e a relação de organização, aparecendo como síntese das duas primeiras: transdução, modulação, organização seriam os três níveis do processo informacional de amplificação, por recrutamento positivo, limitação e descoberta de um sistema de compatibilidade. (SIMONDON, 2010, p. 173, trad. nossa) 
Uma vez aceito esse alastramento hipotético do psicossocial, o que nos diz ainda a distinção de regimes como o físico e o vital? Afirmada a transversalidade da comunicação inventiva, de terceiro nível, como podem se sustentar comunicações de primeiro e segundo níveis?

Lembremos que, para Simondon (2013), a individuação vital se alimenta do que, na individuação física, não deixou de individuar, enquanto a individuação psicossocial surge dos problemas que a vida não cessou de problematizar. Cada regime permite, mediante comunicação, o seu desdobrar noutros regimes. Físico é o que, deixando atrás de si um passado estável, individua somente pelas margens: a individuação física já é questão de fronteira comunicante, em trabalho de atualização de potenciais inerentes à matéria. $\mathrm{O}$ vivo, por sua vez, se repleta de membranas internas e, assim recheado de dobras, converte-se em meio de comunicação para seguir individuando. Na individuação psíquica, finalmente, o transindividual instaura um campo de ressonância afetiva para comunicar potências pré-individuais entre si.

Entendemos que a generalização da relação de tipo social exigiria distinguir os regimes fundamentalmente por sua capacidade de continuar socializando, ou seja, por sua capacidade de sustentar comunicação. Tal molecularização das relações psicossociais daria ensejo para uma microssemiótica na qual os regimes físico e vital já não escapassem ao âmbito do pensamento. Hipótese similar animava a microssociologia de Gabriel Tarde e participa firmemente do gesto fundador da semiótica, que atribui tanto extensão à mente quanto sentimento [feeling] à matéria: em 1901, Peirce (1955, p. 359, trad. nossa) postula um princípio de continuidade para defender que devemos "considerar a matéria como mente cujos hábitos se fixaram de modo a perder os poderes de se formar e de se desmanchar, enquanto a mente deve ser considerada como um gênero químico de complexidade e instabilidade extremas". Matéria e mente se acham aí em um mesmo plano, distinguindo-se por uma questão de dinâmica comunicacional: matéria é mente em situação de equilíbrio, e mente é matéria em trabalho de tradução. O pensamento aí não se enclausura na mente humana, descrevendo antes uma entrada em relação, o ato tradutório enquanto tal, em suas mais diversas modalidades e instâncias: comunicam-se a flor, o sol e a terra, para evocarmos uma imagem de que se servem, cada um à sua maneira, ambos Peirce e Simondon. O aporte peirceano levaria a reconhecer, nos termos do nosso autor, que a individuação física pensa pelas bordas, deixando um passado congelado atrás de si, enquanto a individuação vital internaliza sistemas de pensamento que negociam tra(ns)dução permanente com um meio exterior.

Significação já nomeava, desde a tese de Simondon de 1958, operações orgânicas como o aparecimento inventivo da tridimensionalidade a partir de sinais óticos discrepantes. Não deixa a significação, por isso, de ser uma operação mental. Pelo contrário: é o pensamento que precisa ser repensado para que extrapole o seu confinamento na consciência individuada do sujeito humano e se dinamize como transbordamento 
semiótico transversal a todos os regimes do ser. Da ontogênese à semiogênese ${ }^{3}$, do transbordamento do ser ao transbordamento sígnico.

Embora tratemos de uma filosofia que, entre os seus interesses, evitou privilegiar a linguagem, entendemos que desenvolver uma semiótica simondoniana poderia trazer contribuições para um conjunto importante de discussões, inclusive no que tange ao problema da relação entre o signo e o seu objeto ou referente. Crença comum, afinal, que se desconfie da significação como barreira que afasta o mundo, fazendo muro entre o pensamento e a coisa pensada. Julgamos aprender com Simondon que a significação, pelo contrário, é o que permite e consolida um mundo. Segundo essa leitura, não restaria algum objeto estável (ao qual caberia ao signo corresponder adequadamente) atrás ou antes do ato de significação que o possibilita: antes da significação teríamos uma profusão caótica de perspectivas incompatíveis, sem comunicação entre si. Descarte-se também a perspectiva enquanto individualmente possuída. Na letra estrita da tese de Simondon, uma informação só pode se tornar significativa mediante o coletivo:

Não há diferença entre descobrir uma significação e existir coletivamente com o ser em relação ao qual a significação é descoberta, pois a significação não é do ser, mas entre os seres, ou melhor, através dos seres: ela é transindividual (SIMONDON, 2013, p. 298, trad. nossa).

Mais uma vez, vemos pouca vantagem em tirar daí que a significação chega após os regimes físico e vital. O interessante na exigência do coletivo não é confinar a significação no regime que lhe cabe, mas afirmá-la como acoplamento estruturante. Pelo menos dois termos discrepantes se arranjam de modo a descobrir uma dimensão terceira, mais rica e vasta do que a mera soma ou justaposição das dimensões anteriores. A nova dimensão não pode derivar do que os termos tinham já em comum; somente o conflito comunica e gera o espaço que antes não era.

A significação põe heterogêneos em ressonância: quando Simondon diz que a emoção significa a pluralidade afetiva e que a ação significa a pluralidade perceptiva, trata-se da descoberta de uma dimensão definida pela ressonância de forças discrepantes. Mesmo o presente será compreendido como dimensão que acopla a pluralidade temporal. Nada fica para trás: não se trata de uma resolução por subtração de diferenças. A significação, pelo contrário, é a trama da diferença, o tecido concreto que possibilita o convívio de incompatíveis: "poderia-se dizer, por consequência, que uma verdadeira relação [relation] entre dois termos equivale, de fato, a um vínculo [rapport $]^{4}$ entre três termos" (SIMONDON,

3 Encontramos em Deleuze (1988) uma concepção de signo notavelmente simondoniana, pela qual o signo é a expressão resolutiva de um sistema dissimétrico e sob tensão, que o autor chama de sinal. O signo resultaria, aqui também, de uma comunicação entre disparidades, exprimindo a resolução de um conflito interno de um sistema. Para as aproximações e diferenças entre Simondon e Deleuze nesse aspecto, cf. Sauvagnargues (2009, pp. 239-297).

4 A cuidadosa distinção de Simondon entre relation e rapport, ambas traduzíveis por relação, deve contar entre os principais problemas na tradução deste autor. Optamos neste caso por seguir a edição espanhola, que verte rapport para vínculo (cf. SIMONDON, 2009, p. 93). 
2013, p. 68, trad. nossa), pois o acoplamento de dois termos é já a descoberta de um sistema que os coloca em regime de reciprocidade virtual.

A significação, portanto, nada tem com a transmissão de sinais da teoria matemática da comunicação. Para Shannon e Weaver (1964), mesmo o imprevisível se reporta a um dado código, que o reduz ao improvável. O sinal está compreendido dentro das possibilidades de um sistema, e não poderia ser diferente, pois, naquela teoria, se dirige a um receptor incapaz de assimilar invenção. Tudo se passa como se o sinal já estivesse previsto desde sempre de um lado e de outro.

A harmonia conceitual da teoria matemática da informação se assenta na suposição necessária de um código fixo. Não é missão aqui, como tampouco era para Simondon, objetar sem mais o esquema de Shannon e Weaver. O nosso percurso não encaminha alguma refutação do código, mas antes o seu avivamento interno, que é a própria condição de sua propagação. Um código estável promete o regime físico ou morto da comunicação, o que, a rigor, nunca será o caso. Mas a afirmação do metaestável contra o estável não nos coloca em uma filosofia do completo desequilíbrio: mesmo a invenção, já o vimos, vem com um senso de autoconstituição de normas. À rigidez do código, o sistema metaestável não opõe uma sopa primordial pré-individual. Um sistema, ainda que desequilibrado, sustenta normatividades internas; a questão é que, em Simondon, o conceito de informação recua para dar conta do colapso e do nascimento da normatividade. Andrea Bardin (2015) nota que a concepção cibernética da informação sofre de um duplo fetichismo, identitário e determinista, que a leva a confundir sinal e informação, enquanto, para Simondon, a informação interrompe o funcionamento autorregulatório de um sistema, reconfigurando-o.

\section{Considerações finais}

Retomemos o plano desenvolvido neste artigo. A teoria matemática da comunicação se atribuía de saída a missão de afetar, mas excluía de seu diagrama o afeto e a transformação. Enfrentando o diagrama desde o seu interior, Simondon igualava informação a uma transformação cujo requisito era a existência de um sistema com potenciais internos, explicados por uma dissimetria fundamental sem a qual não pode haver mudança: a diferença é condição da comunicação. A transformação dependia, ainda, de um acontecimento disparador, definido em um encontro no qual se distribuíam os papéis recíprocos de singularidade codificante e receptor plástico, encontro este que não precisaria se dar entre dois sistemas, mas ocorrer no interior de um mesmo sistema em situação de equilíbrio metaestável. Em uma escalada de sinais estáveis até a significação inventiva, eram três os níveis da comunicação, e deles derivamos os seguintes verbos: escolher/preferir; discernir/codificar; aprender/inventar. A teoria da individuação 
e a universalização das relações de tipo psicossocial permitiam distinguir os níveis de comunicação segundo a sua capacidade de continuar inventando.

Entendemos ser crucial colocar Simondon em novos encontros se quisermos liberar esta teoria da comunicação de categorias tão restritivas quanto a de receptor. Em todo caso, é sempre ao custo de reelaborações decisivas que Simondon escolhe sustentar os conceitos de outrem. Ressaltemos, em tempo ainda de fechar esta seção, que não há passividade no receptor simondoniano. Um acontecimento inventivo precede toda estruturação. Um sistema vivo não é vítima indefesa diante das singularidades nas quais esbarra - ele é cocriador ativo das soluções de seus enfrentamentos. Se o indivíduo não constitui uma substância completamente autônoma e idêntica a si mesma, ele também não é o signo passivo de uma imanência, nele, das formas do mundo. Em última instância, as teses da liberdade individual e do condicionamento social só distribuem inversamente os seus polos ativo e inativo, o que leva, de um lado, o individualismo a perder de vista toda relação digna do nome, e, do outro, o coletivismo a negligenciar a invenção. A significação aponta para um poder impessoal de autoconstituição de indivíduos-meio. Os lugares do eu e do outro aí se complexificam, pois toda relação é simultaneamente exterior e interior ao indivíduo: "a significação não é do ser, mas entre os seres, ou ainda através dos seres: ela é transindividual” (SIMONDON, 2013, p. 298, trad. nossa).

Demétrio Rocha Pereira é doutorando no Programa de Comunicação e Informação na Universidade Federal do Rio Grande do Sul (UFRGS).

demetrio.pereira@gmail.com

\section{Referências}

BARDIN, A. Epistemology and Political Philosophy in Gilbert Simondon: Individuation, Technics, Social Systems. Dordrecht: Springer, 2015.

BERLO, D. K. O processo da comunicação: introdução à teoria e à prática. São Paulo: Martins Fontes, 1999.

CHATEAU, J-Y. Communication et information dans I'oeuvre de Gilbert Simondon. In: SIMONDON, Gilbert. Communication et information: Cours et Conférences. Chatou: Les Éditions de La Transparence, 2010.

DELEUZE, G. Diferença e Repetição. Rio de Janeiro: Graal, 1988.

MELO, J. M. de. A recepção das ideias de Wilbur Schramm no Brasil. In: Revista Asociación Latinoamericana de Investigadores de La Comunicación (Alaic), ano IV, número 6, junho de 2007. Disponível em: http://www.eca.usp.br/associa/alaic/revista/r6/art_01.pdf. Acesso: 26 de janeiro de 2019.

PEIRCE, C. S. Philosophical writings of Peirce. Nova York: Dover Publications, 1955.

SAUSSURE, F. de. Curso de linguística geral. São Paulo: Cultrix, 2006. 
SAUVAGNARGUES, A. Deleuze: L'empirisme transcendantal. Paris: Presses Universitaire de France, 2009.

SCHRAMM, W. (org.). The Process and Effects of Mass Communications. Urbana: University of Illinois Press, 1955.

SHANNON, C. E.; WEAVER, W. The Mathematical Theory of Communication. Urbana: The University of Illinois Press, 1964.

SIMONDON, G. L'individuation à la lumière des notions de forme et d'information. Grenoble: Éditions Jérôme Millon, 2013.

. La individuación a la luz de las nociones de forma y de información. Buenos Aires: Ediciones La Cebra y Editorial Cactus, 2009.

Communication et information: Cours et Conférences. Chatou: Les Éditions de La Transparence, 2010.

Curso sobre la percepción. Buenos Aires: Cactus, 2012.

Artigo recebido em 11/04/2019

e aprovado em 20/06/2019. 